LARA, F.M.; SCARANELLO, A.L.; BALDIN, E.L.L.; BOIÇA JÚNIOR, A.L.; LOURENÇÃO, A.L. Resistência de genótipos de batata a larvas e adultos de Diabrotica speciosa. Horticultura Brasileira, Brasília, v.22, n.4, p.761-765, out-dez 2004.

\title{
Resistência de genótipos de batata a larvas e adultos de Diabrotica speciosa
}

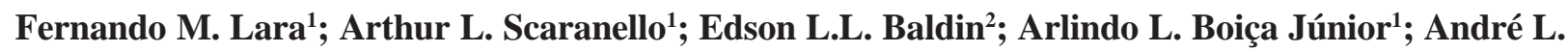 \\ Lourenção ${ }^{3}$ \\ ${ }^{1}$ UNESP, Depto. Fitossanidade, Via de Acesso Prof. Paulo Donato Castellane, s/nº, 14884-900 Jaboticabal-SP; E-mail: \\ fmlara@fcav.unesp.br; ${ }^{2}$ UNICASTELO, FCA, Lab. Entomologia, Estrada Projetada F1 s/nº 15600-000 Fernandópolis-SP; E-mail: \\ elbaldin@terra.com.br; ${ }^{3}$ Instituto Agronômico, C. postal 28, 13001-970 Campinas-SP; E-mail: andre@ iac.sp.gov.br
}

\section{RESUMO}

Avaliaram-se os danos causados por larvas e por adultos de Diabrotica speciosa (Germar) sobre tubérculos e folhas de quatorze genótipos de batata, através de ensaios com e sem chance de escolha, realizados no período de 2000 a 2002, sob condições de campo e de laboratório. Utilizaram-se os genótipos Achat, Apuã, Aracy, Aracy Ruiva, Ibitu Açu, Itararé, Bintje, N 140-201, NYL 235-4, 288.776-6, 288.814-7, 288.719-13, 288.794-19 e 288.801-6. Em ensaios onde se avaliou o dano provocado por larvas nos tubérculos, observou-se alta resistência em 'NYL 235-4' e '288.776-6', enquanto que Aracy, Apuã e Itararé revelaram-se suscetíveis. Em ensaios de preferência para alimentação com adultos de $D$. speciosa, constatou-se altos níveis de resistência em 'NYL 235-4', 'Itararé', '288.794-19' e '288.801-6'; no genótipo 288.814-7 foi observada resistência moderada, sendo que 'Achat', 'Bintje' e '288.719-13' mostraram-se altamente suscetíveis.

Palavras-chave: Solanum tuberosum, vaquinha, Chrysomelidae, resistência de plantas a insetos.

\begin{abstract}
Resistance of potato genotypes to larvae and adults of Diabrotica speciosa

The damage caused by larvae and adults of Diabrotica speciosa (Germar) was evaluated on tubers and leaves of fourteen potato genotypes, under free and no choice tests, during the years 2000 to 2002, under field and laboratory conditions. The genotypes Achat, Apuã, Aracy, Aracy Ruiva, Ibitu Açu, Itararé, Bintje, N 140-201, NYL 235-4, 288.776-6, 288.814-7, 288.719-13, 288.794-19 and 288.801-6 were evaluated. In damage assays with larvae, high level of resistance was observed in NYL 235-4 and 288.776-6 genotypes, while Aracy, Apuã and Itararé were susceptible. In feeding preference assays with adults of D. speciosa, NYL 235-4, Itararé, 288.794-19 and 288.801-6 genotypes showed to be the most resistant; moderate resistance was observed in 288.814-7 genotype. 'Achat', 'Bintje' and '288.719-13' were the most susceptible to Diabrotica speciosa.
\end{abstract}

Keywords: Solanum tuberosum, Chrysomelidae, host plant resistance.

\section{(Recebido para publicação em 5 de julho de 2003 e aceito em 8 de agosto de 2004)}

$\mathrm{E}$ stima-se a existência de mais de 200 espécies de batatas silvestres e oito espécies botânicas cultivadas, destacando-se, dentre as últimas, a espécie Solanum tuberosum L. que possui maior interesse econômico e que vem sendo cultivada na maioria dos países produtores (Filgueira, 2000).

Dentre os problemas que limitam o cultivo desta espécie, destacam-se doenças e pragas, cujo controle químico requer gastos elevados que giram em torno de $19 \%$ do custo de produção (Curzio, 1993). Juntamente com os pulgões Myzus persicae (Sulz.) e Macrosiphum euphorbiae (Thomas); e as traças Phthorimaea operculella (Zel.) e Tuta absoluta (Meir.); as vaquinhas Diabrotica sp. e Epicauta atomaria (Germ.) são apontadas como as principais pragas da cultura, sendo seu grau de importância variável de uma região para outra podendo reduzir a produção em até 33\% (França e Barbosa, 1987).
A espécie D. speciosa ocorre em vários países produtores de feijão e outras leguminosas nas Américas (Souza, 1987). No Brasil, encontra-se difundida em todo território nacional, sendo considerada praga principal ou secundária de várias culturas (Lorenzato, 1984; Magalhães e Carvalho, 1988), em especial leguminosas, cucurbitáceas e solanáceas. As larvas desse inseto causam danos nos tubérculos e nas plantas, na fase de brotação e emergência (Ferro e Boiteau, 1993). Os adultos alimentam-se das folhas e possuem o hábito constante de voar de uma planta para outra. De acordo com Cranshaw E Radcliffe (1980), quando os adultos promovem desfolha de até $35 \%$ no início do ciclo da cultura, a planta consegue boa recuperação, porém, se a mesma for mais intensa, próxima ou acima de 70, as perdas na produção serão significativas.

Em face dos efeitos indesejáveis do uso de inseticidas, outros métodos de controle das pragas da batata vêm sendo analisados. Um deles, bem promissor, é o uso de plantas resistentes, que oferece uma série de vantagens, inclusive a de se integrar perfeitamente em programas de manejo de pragas, conforme se pode observar em inúmeros exemplos citados por Lara (1991).

O presente trabalho objetivou avaliar a resistência de genótipos de batata, abrangendo linhagens introduzidas dos EUA e/ou melhoradas pela Embrapa Hortaliças e cultivares, ao crisomelídeo D. speciosa, em condições de campo, e a preferência alimentar de adultos, em laboratório.

\section{MATERIAL E MÉTODOS}

Os ensaios foram conduzidos em Jaboticabal (SP), na UNESP, de 2000 a 2002. Os genótipos avaliados compreenderam sete cultivares (Achat, Apuã, Aracy, Aracy Ruiva, Bintje, Ibitu Açu e 
Itararé) e sete linhagens derivadas de $S$. berthaultii (N 140-201, NYL 235-4, 288.719-13, 288.776-6, 288.794-19, 288.801-6 e 288.814-7), em fase de melhoramento pela Universidade de Cornell (EUA) e Embrapa Hortaliças.

\section{Resistência de genótipos a larvas}

Instalou-se um ensaio de campo, com chance de escolha, em início de maio de 2000, utilizando-se os genótipos Achat, Apuã, Aracy, Aracy Ruiva, Ibitu Açu, Itararé, NYL 235-4 e 288.776-6. Os materiais foram semeados em quatro blocos casualizados, com parcelas de três ruas de $3 \mathrm{~m}$ de comprimento e espaçadas de $0,7 \mathrm{~m}$, com sete plantas por rua; a área experimental foi cercada com a cultivar Bintje. Durante a colheita foram avaliados os danos causados pelas larvas, pela contagem do número de furos existentes nos tubérculos, amostrando-se 15 tubérculos/parcela, colhidos ao acaso. Em 2001, instalouse outro ensaio semelhante, com plantio também em início de maio. Nesse utilizaram-se os genótipos Aracy Ruiva, Bintje, Ibitu Açu, Itararé, NYL 235 4 e 288.814-7, sendo toda a área experimental delimitada com Achat. Durante a colheita foram avaliados os danos causados pelas larvas aos tubérculos, amostrando-se, neste caso, 20 tubérculos/parcela, colhidos ao acaso.

Preferência para alimentação de adultos

Em julho e agosto de 2000, foram realizados ensaios em condições de laboratório, com e sem chance de escolha, avaliando-se os genótipos Achat, Apuã, Aracy, Aracy Ruiva, Bintje, Ibitu Açu, Itararé, NYL 235-4 e 288.776-6, que se encontravam plantados no campo (do primeiro ensaio com larvas). Os ensaios foram mantidos no interior de B.O.D.s, sob temperatura de $25 \pm 2^{\circ} \mathrm{C}$ e escotofase de $24 \mathrm{~h}$. No teste com chance de escolha utilizaram-se discos de folíolos, um de cada genótipo, com 2,54 $\mathrm{cm}^{2}$ de diâmetro, os quais foram colocados em placa de Petri, formando um círculo periférico, sobre papel umedecido. Devido ao número de genótipos, o ensaio foi dividido em duas etapas, mantendo-se a cultivar Bintje como padrão, para posteriormente calcular-se o Índice de Preferência, utilizando-se a seguinte equação (Kogan e Goeden,
1970): IP = 2G / (G+P), onde IP= Índice de preferência alimentar; $G=$ Genótipo em estudo; P= Genótipo padrão (Bintje). Esse índice varia de 0,00 a 2,00, considerando-o igual a 1,00 no genótipo padrão. Em cada placa foram colocados discos de folíolos de cinco dos genótipos em estudo (incluindo-se Bintje) e liberados dez adultos de $D$. speciosa, que ali permaneceram até que um dos discos apresentasse $75 \%$ da área consumida, momento em que os insetos foram retirados, medindo-se o consumo utilizando-se medidor de área foliar (Li-cor). No início do ensaio, foram mantidos discos de cada genótipo, em mesmas condições, e que também foram medidos ao final do teste, como padrões, com o objetivo de se corrigir eventual variação de área dos folíolos. Foram utilizadas oito repetições em delineamento inteiramente casualizado, com plantas aos 55 dias após o plantio. O teste sem chance de escolha foi conduzido da mesma maneira que o anterior, utilizando-se, porém, apenas um dos materiais por placa de Petri, colocando-se dois discos no interior de cada uma e quatro insetos por placa. Efetuaram-se oito repetições com plantas aos 60 dias após o plantio.

Em 2001, foram novamente efetuados testes de preferência para alimentação, com e sem chance de escolha, com os genótipos que se encontravam no ensaio de campo, Aracy Ruiva, Bintje, Ibitu Açu, Itararé, NYL 235-4 e 288.814-7. Os ensaios foram instalados em delineamento inteiramente casualizado, realizando-se 15 repetições para ambos, com plantas aos 30, 45 e 60 dias após o plantio. Nesses testes foram avaliadas as áreas foliares consumidas.

Esses mesmos genótipos (segundo ensaio com larvas) foram avaliados com plantas em vasos, aos 30 dias após o plantio, cobertas com tecido "voil", em condições de casa-de-vegetação, sem chance de escolha, num delineamento em seis blocos casualizados. Em cada gaiola (planta) foram liberados 15 insetos, os quais foram coletados em campo e mantidos sem alimentação durante 24 horas antes do início do teste. No caso de morte ou desaparecimento, o inseto era reposto. Efetuou-se a avaliação da área foliar consumida/planta após quatro dias e meio, quando, mediante estimativa visual, verificou-se que algumas das repetições apresentavam um nível maior de destruição da área foliar, em relação às outras, dentro de tratamentos diferentes. Em 2000, também foram conduzidos ensaios semelhantes aos realizados com genótipos comerciais naquele ano, com e sem chance de escolha, a partir de plantio de campo, com linhagens em fase de melhoramento e mantendo-se Bintje como padrão. Foram realizadas oito repetições em cada ensaio, utilizando-se Bintje, N 140-201, NYL 235-4, 288.719-13, 288.776-6, 288.794-19, 288.801-6 e 288.814-7. Em 2002, efetuou-se outro ensaio sem chance de escolha, envolvendo as cultivares Achat, Aracy Ruiva e Itararé, e as linhagens NYL 235-4, 288.794-19 e 288.814-7. O plantio foi realizado em vasos em meados de julho. O experimento foi montado no final de agosto, com 6 repetições, utilizando-se 1 disco/ placa e 2 insetos adultos.

Os dados obtidos foram submetidos a análise de variância, sendo as médias comparadas pelo teste de Tukey, ao nível de 5\% de probabilidade. Quando necessário, os dados originais $(\mathrm{x}$ ) foram transformados para $\ln (\mathrm{x}+5)$ e arc sen $(\mathrm{x}+0,5)^{1 / 2}$.

\section{RESULTADOS E DISCUSSÃO}

\section{Resistência de genótipos às larvas}

Quanto aos danos nos tubérculos, no ensaio de 2000, os genótipos 288.776-6 e NYL 235-4 revelaram-se os mais resistentes, com 6,8 e 6,9 furos/tubérculo, enquanto os mais suscetíveis foram Apuã e Aracy, apresentando 13 ou mais furos por tubérculo (Tabela 1). Sargo e Lara (1999), em ensaios semelhantes realizados em 1996 e 1997, no mesmo local, destacaram o genótipo NYL 2354 como o menos atacado diante dos outros materiais avaliados. Lara et al. (2000) também observaram baixo número de furos por tubérculo nos genótipos NYL 235-4, 288.776-6 e 288.801-8. No ensaio de 2001, com a maioria desses mesmos genótipos (Tabela 1), novamente NYL 235-4 destacou-se como menos atacado (1,2 furos/ tubérculo). Já os genótipos Itararé e 
288.814-7 foram os mais atacados, com 9,7 e 8,6 furos por tubérculo respectivamente. Lara et al. (2000) também verificaram alta suscetibilidade às larvas nesse último genótipo.

\section{Preferência para alimentação de adultos}

Os índices de preferência (IP) revelaram que $D$. speciosa apresentou menor preferência para alimentação $(0,76)$ no genótipo NYL 235-4, enquanto Bintje foi o genótipo mais consumido (Tabela 2, Ensaios A). Os índices dos demais genótipos foram intermediários, não diferindo de NYL 235-4 e do padrão Bintje. No teste sem chance, houve diferença somente entre o genótipo Itararé $\left(0,73 \mathrm{~cm}^{2}\right)$, e a cultivar Achat $\left(1,62 \mathrm{~cm}^{2}\right)$. O segundo menor consumo foi constatado em NYL 235-4 $\left(0,92 \mathrm{~cm}^{2}\right)$, sem diferir, todavia, dos demais genótipos. Uma análise conjunta dos resultados dos ensaios com e sem chance de escolha, sugere que Itararé e NYL 235-4 apresentam resistência a adultos de $D$. speciosa, do tipo não-preferência para alimentação.

Os resultados dos ensaios com e sem chance de escolha, realizados em 2001 com alguns desses genótipos, para verificar-se a repetibilidade, com folíolos aos 30, 45 e 60 dias após o plantio, encontram-se na Tabela 3. Nota-se que no teste com chance de escolha, com folíolos aos 30 dias, os genótipos NYL 235-4 e 288.814-7 foram menos consumidos que Aracy Ruiva, não apresentando diferença dos demais. Com folíolos aos 45 dias, destacaram-se NYL 235-4 e Itararé com consumo menor que o observado em Bintje. Com folíolos aos 60 dias, não se detectou diferença significativa entre os genótipos. No teste sem chance de escolha, o genótipo NYL 235-4 foi o menos preferido para alimentação (folíolos aos 30 dias), sendo semelhante somente ao 288.814-7. Já aos 45 dias, somente NYL 235-4 e Itararé foram menos consumidos que Bintje. Com os folíolos aos 60 dias, novamente não se detectou diferença significativa entre os genótipos. Considerando-se as médias de consumo das três idades dos folíolos, dos dois tipos de testes, observou-se que NYL 235-4 foi o menos preferido pelos adultos de $D$. speciosa, seguido de Itararé e 288.814-7, enquanto Bintje foi o mais preferido,

Tabela 1. Dano médio de larvas de D. speciosa em tubérculos de batata obtidos em experimentos de campo por dois anos consecutivos. Jaboticabal, UNESP, 2001 e 2002.

\begin{tabular}{lcc}
\hline \multirow{2}{*}{ Genótipo } & \multicolumn{2}{c}{ Danos (furos/tubérculo) } \\
\cline { 2 - 3 } & $\mathbf{2 0 0 0 ^ { \mathbf { 2 } }}$ & $\mathbf{2 0 0 1}^{\mathbf{2}}$ \\
\hline Apuã & $13,8 \mathrm{a}$ & - \\
Aracy & $13,0 \mathrm{ab}$ & - \\
Itararé & $11,2 \mathrm{abc}$ & $9,7 \mathrm{a}$ \\
Ibitu Açu & $9,0 \mathrm{abc}$ & $8,1 \mathrm{ab}$ \\
Achat & $8,0 \mathrm{bc}$ & - \\
Aracy Ruiva & $7,8 \mathrm{bc}$ & $4,7 \mathrm{~b}$ \\
NYL 235-4 & $6,9 \mathrm{c}$ & $1,2 \mathrm{C}$ \\
$288.776-6$ & $6,8 \mathrm{c}$ & - \\
Bintje & - & $6,3 \mathrm{ab}$ \\
$288.814-7$ & - & $8,6 \mathrm{ab}$ \\
\hline F & $5,58{ }^{*}$ & 28,04 \\
\hline C.V. $(\%)$ & 4,59 & 5,83
\end{tabular}

${ }^{1 /}$ Dados originais; para análise estatística foram transformados em $\ln (\mathrm{x}+5) ;{ }^{2 /}$ Médias seguidas de mesma letra, na coluna, não diferem entre si (Tukey, 5\%).

Tabela 2. Médias de índice de preferência (IP) e consumo de área foliar de genótipos de batata por D. speciosa, em testes com e sem chance de escolha, em laboratório. Jaboticabal, UNESP, 2000.

\begin{tabular}{|c|c|c|}
\hline \multicolumn{3}{|c|}{ Ensaio A } \\
\hline \multirow{2}{*}{ Genótipo } & \multicolumn{2}{|c|}{ Consumo $^{1}$} \\
\hline & Com chance (IP) ${ }^{2}$ & Sem chance $\left(\mathrm{cm}^{2}\right)^{2}$ \\
\hline Bintje & $1,00 \mathrm{a}$ & $1,31 \mathrm{ab}$ \\
\hline Aracy & $0,97 a b$ & $1,36 a b$ \\
\hline Achat & $0,94 a b$ & $1,62 \mathrm{a}$ \\
\hline Apuã & $0,92 a b$ & $1,35 a b$ \\
\hline $288.776-6$ & $0,90 a b$ & $1,18 \mathrm{ab}$ \\
\hline Ibitu Açu & $0,86 a b$ & $1,22 \mathrm{ab}$ \\
\hline Itararé & $0,84 a b$ & $0,73 \mathrm{~b}$ \\
\hline Aracy Ruiva & $0,83 a b$ & $1,13 \mathrm{ab}$ \\
\hline NYL 235-4 & $0,76 \mathrm{~b}$ & $0,92 a b$ \\
\hline$F$ & 2,49 * & 3,76 * \\
\hline C.V. $(\%)$ & 8,34 & 3,92 \\
\hline \multicolumn{3}{|c|}{ Ensaio B } \\
\hline \multirow{2}{*}{ Genótipo } & \multicolumn{2}{|c|}{ Consumo $^{1}$} \\
\hline & Com chance (IP) ${ }^{2}$ & Sem chance $\left(\mathrm{cm}^{2}\right)^{2}$ \\
\hline $288.776-6$ & $1,27 \mathrm{a}$ & $1,37 \mathrm{ab}$ \\
\hline $288.824-7$ & $1,16 a b$ & $1,43 a b$ \\
\hline N 140-201 & $1,08 a b$ & $1,86 a b$ \\
\hline $288.719-13$ & $1,02 a b$ & $2,10 a$ \\
\hline Bintje & $1,00 \mathrm{ab}$ & $1,69 a b$ \\
\hline NYL 235-4 & $0,89 a b$ & $1,36 a b$ \\
\hline 288.794-19 & $0,86 a b$ & $1,16 \mathrm{~b}$ \\
\hline 288.801-6 & $0,71 \mathrm{~b}$ & $1,48 a b$ \\
\hline$F$ & 2,79 * & 2,83 * \\
\hline C.V. (\%) & 9,46 & 4,11 \\
\hline
\end{tabular}

${ }^{1 /}$ Dados originais. Para análise estatística foram transformados em $\ln (\mathrm{x}+5) ;{ }^{2 /}$ Médias seguidas de mesma letra, na coluna, não diferem entre si (Tukey, 5\%).

embora essas médias não tenham sido estatisticamente diferentes. Lara et al. (2000) também verificaram baixo consumo de adultos (em campo e labora- tório) em 288.814-7, enquanto em NYL 235-4 o consumo foi intermediário, mas sem diferir significativamente daquela linhagem. 
Tabela 3. Consumo médio de área foliar de genótipos de batata por $D$. speciosa, em folíolos colhidos aos 30, 45 e 60 dias após o plantio, em laboratório. Jaboticabal, UNESP, 2001.

\begin{tabular}{|c|c|c|c|}
\hline \multicolumn{4}{|c|}{ Testes com chance de escolha } \\
\hline \multirow{2}{*}{ Genótipo } & \multicolumn{3}{|c|}{ Área consumida $\left(\mathrm{cm}^{2}\right)^{1}$} \\
\hline & 30 dias $^{2}$ & 45 dias $^{2}$ & 60 dias $^{2}$ \\
\hline Aracy Ruiva & $2,94 \mathrm{a}$ & $1,48 a b$ & 1,15 \\
\hline Ibitu Açu & $2,23 a b$ & $1,55 a b$ & 1,94 \\
\hline Itararé & $2,08 a b$ & $1,24 \mathrm{~b}$ & 1,20 \\
\hline Bintje & $2,07 \mathrm{ab}$ & $2,28 \mathrm{a}$ & 1,57 \\
\hline 288.814-7 & $1,67 \mathrm{~b}$ & $1,60 a b$ & 1,88 \\
\hline NYL 235-4 & $1,32 \mathrm{~b}$ & $1,02 \mathrm{~b}$ & 1,55 \\
\hline $\bar{F}$ & 4,56 * & 3,68 * & $1,25^{\mathrm{ns}}$ \\
\hline C.V. (\%) & 6,96 & 6,03 & 7,48 \\
\hline \multicolumn{4}{|c|}{ Testes sem chance de escolha } \\
\hline \multirow{2}{*}{ Genótipo } & \multicolumn{3}{|c|}{ Área consumida $\left(\mathrm{cm}^{2}\right)^{1}$} \\
\hline & 30 dias $^{2}$ & 45 dias $^{2}$ & 60 dias $^{2}$ \\
\hline Bintje & $2,14 \mathrm{a}$ & $2,33 \mathrm{a}$ & 2,13 \\
\hline Ibitu Açu & $2,12 \mathrm{a}$ & $2,16 \mathrm{a}$ & 1,53 \\
\hline Itararé & $1,97 \mathrm{a}$ & $1,62 a b$ & 1,33 \\
\hline Aracy Ruiva & $1,91 \mathrm{a}$ & $1,79 a b$ & 1,86 \\
\hline $288.814-7$ & $1,72 a b$ & $1,43 a b$ & 1,74 \\
\hline NYL 235-4 & $1,10 \mathrm{~b}$ & $1,23 \mathrm{~b}$ & 1,95 \\
\hline $\mathrm{F}$ & 4,23 * & 3,53 * & $1,13^{\mathrm{ns}}$ \\
\hline C.V. (\%) & 5,71 & 5,85 & 6,47 \\
\hline
\end{tabular}

${ }^{1 /}$ Dados originais. Para análise estatística foram transformados em $\ln (\mathrm{x}+5) ;{ }^{2 /}$ Médias seguidas de mesma letra, na coluna, não diferem entre si (Tukey, 5\%).

Tabela 4. Médias de área e da correspondente percentagem foliar consumida por D. speciosa, em plantas de genótipos de batata aos 30 dias após o plantio, em teste sem chance de escolha, em casa de vegetação. Jaboticabal, UNESP, 2000.

\begin{tabular}{lcc}
\hline \multirow{2}{*}{ Genótipo } & \multicolumn{2}{c}{ Consumo $^{\mathbf{1}}$} \\
\cline { 2 - 3 } & $\mathbf{( c m}^{\mathbf{2}} \mathbf{~}^{\mathbf{2}}$ & $\mathbf{( \% ) ^ { \mathbf { 2 } }}$ \\
\hline $288.814-7$ & $158,55 \mathrm{a}$ & $11,18 \mathrm{a}$ \\
Ibitu Açu & $135,66 \mathrm{ab}$ & $8,36 \mathrm{ab}$ \\
Bintje & $134,92 \mathrm{ab}$ & $9,53 \mathrm{ab}$ \\
Aracy Ruiva & $124,05 \mathrm{ab}$ & $8,99 \mathrm{ab}$ \\
Itararé & $110,47 \mathrm{ab}$ & $7,06 \mathrm{ab}$ \\
NYL 235-4 & $82,98 \mathrm{~b}$ & $5,61 \mathrm{~b}$ \\
\hline F & $3,63{ }^{*}$ & $4,00{ }^{*}$ \\
\hline C.V. (\%) & 6,45 & 9,41
\end{tabular}

${ }^{1 /}$ Dados originais; para análise estatística os dados de área foram transformados em $\ln (\mathrm{x}+5)$ e os de $\%$ em arc sen $(x+5)^{1 / 2} ;{ }^{2 /}$ Médias seguidas de mesma letra, na coluna, não diferem entre si (Tukey, 5\%).

No ensaio sem chance de escolha realizado com esses genótipos, em casade-vegetação, com plantas aos 30 dias após o plantio (Tabela 4), NYL 235-4 foi menos atacado, diferindo estatisticamente de 288.814-7 e apresentando $82,98 \mathrm{~cm}^{2}$ de área foliar destruída, equivalente a $5,61 \%$ da planta, enquanto em 288.814-7 os insetos consumiram praticamente o dobro da área foliar, sendo genótipo apresentou-se como moderadamente resistente. Dessa forma, tornase necessária sua reavaliação em novos ensaios. Deve-se destacar também que Itararé foi o segundo genótipo menos atacado, embora sem apresentar diferenças significativas dos extremos, reforçando o fato de que, entre os comerciais, essa cultivar apresenta moderada resistência a adultos de D. speciosa.

Os dados dos ensaios com e sem chance de escolha realizados em 2000, com as sete linhagens e a cultivar Bintje, encontram-se na Tabela 2 (Ensaios B). Observa-se que no teste com chance de escolha destacou-se o genótipo 288.801-6 como menos preferido (IP = 0,71), seguido por 288.794$19(\mathrm{IP}=0,86)$ e NYL 235-4 (IP = 0,89). O genótipo 288.776-6 foi o mais preferido (IP = 1,27), mas diferiu apenas de 288.801-6. No ensaio sem chance de escolha, 288.794-19 foi menos preferido para alimentação do que o 288.719-13, sendo que nenhum deles diferiu dos demais. Convém ressaltar que 288.719-13, suscetível, é o único genótipo deste ensaio que possui tricomas glandulares funcionais e que essa característica parece não interferir na alimentação dos adultos de $D$. speciosa. De acordo com os dados obtidos em 2002, com três cultivares e três linhagens (Figura 1) houve menor consumo foliar no genótipo 288.814-7, diferindo significativamente de Itararé e de Achat, que apresentaram maiores médias de consumo, e confirmando o comportamento de resistência observado nessa linhagem em teste com chance de escolha, utilizando-se folíolos de 30 dias (Tabela 3). Ainda, observa-se que os genótipos Aracy Ruiva, NYL 235-4 e 288.794-19 apresentaram moderada resistência, também diferindo do genótipo suscetível Achat.

Considerando-se todos os experimentos realizados, pode-se inferir que NYL 235-4 e 288.776-6 apresentam alta resistência aos danos de larvas de $D$. speciosa nos tubérculos, e que Aracy Ruiva apresenta resistência moderada, enquanto Aracy, Apuã e Itararé são suscetíveis. Enfocando-se os adultos dessa espécie, verifica-se que Itararé, NYL 


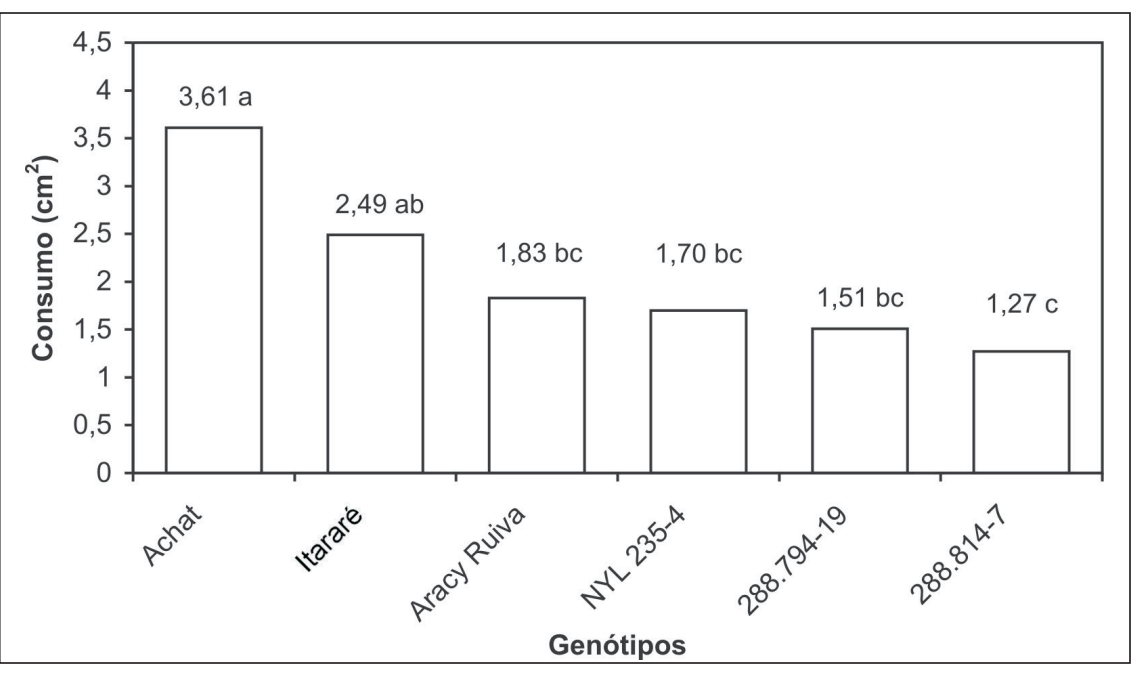

Figura 1. Consumo médio de área foliar de genótipos de batata por D. speciosa, em teste sem chance de escolha, em folíolos colhidos aos 40 dias após o plantio, em laboratório. Jaboticabal, UNESP, 2002.

235-4, 288.794-19 e 288.801-6 apresentam resistência do tipo não-preferência para alimentação, enquanto 288.814-7 mostra resistência em nível moderado e Achat, Bintje e 288.719-13 são suscetíveis.

\section{AGRADECIMENTOS}

Os autores expressam seus agradecimentos ao CNPq e à FAPESP, pelas bolsas, e a Embrapa Hortaliças pelo fornecimento de sementes.

CRANSHAW, W.S.; RADCLIFFE, E.B. Effect of defoliation on yield of potatoes. Journal of Economic Entomology, v.73, p.131-4, 1980. CURZIO, I. Produzindo mais e melhor. Sinal Verde, v.12, p.2-6, 1993.

FERRO, D.N.; BOITEAU, G. Management of insect pests. In: ROWE, R. C. (ed.) Potato health management. Wooster: APS, 1993. p.103-116.

FILGUEIRA, F.A.R. Novo manual de olericultura: agrotecnologia moderna na produção e comercialização de hortaliças. Viçosa: UFV.
FRANÇA, F.H.; BARBOSA, S. O controle de pragas da batata. p.73-84. In: REIFSCHENEIDER, F.J.B.(ed). Produção de Batata. Brasília. 239 p, 1987.

KOGAN, M.; GOEDEN, R.D. The host-plant range of Lema trilineata daturaphila (Coleoptera: Chrysomelidae). Annals of Entomological Society of America, v.63, p.1175-1180, 1970.

LARA, F.M. Princípios de Resistência de Plantas a Insetos. $2^{\text {a }}$ ed., São Paulo: Ícone Editora, 336 p, 1991.

LARA, F.M.; POLETTI, M.; BARBOSA, J.C. Resistência de genótipos de batata (Solanum spp.) a Diabrotica speciosa (Germar, 1824) (Coleoptera: Chrysomelidae) e preferência alimentar de adultos. Ciência Rural, Santa Maria, v.30, p.927-931, 2000. LORENZATO, D. Controle integrado de Diabrotica speciosa (Germar, 1824) em frutíferas de clima temperado com cairomônio encontrado em raízes de plantas nativas da família Cucurbitaceae. In: CONGRESSO BRASILEIRO DE FRUTICULTURA, 7, Florianópolis. Anais... Florianópolis:SBF, 1984. p.347-355.

MAGALHÃES, B.P.; CARVALHO, S.M. Insetos associados à cultura, p. 573-589. In: ZIMMERMANN, M.J.O.; ROCHA, M.; YAMADA, T. (eds.), Cultura do feijoeiro - fatores que afetam a produtividade. Piracicaba, Associação Brasileira para pesquisa da Potassa e do Fosfato, 589 p, 1988. p.157-188, 2000. 420 p.
SARGO, H.L.B ; LARA, F.M. Resistência de genótipos de batata (Solanum spp.) a larvas e adultos de Diabrotica speciosa (Germar) (Coleoptera: Chrysomelidae). Científica, Jaboticabal, v.27, p.177-186, 1999.

SOUZA, L.A. Parâmetros para detectar a resistência de feijoeiro a Diabrotica speciosa, Cerotoma e Empoasca kraemeri. Pesquisa Agropecuária Brasileira, Brasília, v.22, p.2729, 1987. 